\title{
Finite state representation of reduplication processes in Igbo
}

\author{
Publisher: IEEE
}

Cite This

\section{2}

Author(s)

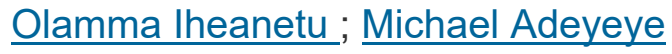

\begin{abstract}
:
This paper presents a finite state model of reduplication processes in Igbo. Identified Igbo reduplication processes are based on (i) verbal reduplication with prefixation, (ii) total nominal reduplication (iii) ideophone reduplication. However, this work identifies and includes a fourth and fifth type that occurs in the language, namely; (iv) adverbial reduplication and ( $v$ ) prepositional reduplication. Xerox Finite State Tool (XFST) was used in representing the five Igbo reduplication processes computationally. Igbo verbal reduplication exhibits selective reduplication process and is characterized by prefixation and vowel replacement. Vowel harmony phenomenon was taken into consideration in achieving verbal reduplication to cater for phonological changes. Model testing results showed $84 \%$ accuracy in both analysis and recognition of reduplicated forms in Igbo.
\end{abstract}

Published in: 2013 Africon

Date of Conference: 9-12 Sept. 2013

Date Added to IEEE Xplore: 06 March 2014

ISBN Information:

ISSN Information:

INSPEC Accession Number: 14147209

DOI: $10.1109 / A F R C O N .2013 .6757772$

Publisher: IEEE

Conference Location: Pointe-Aux-Piments, Mauritius

\section{Introduction}

Morphology is the lowest level of linguistic analysis. It is concerned with the rules of word formation in a language. Derived from the Greek word morphe, morphology implies shape or form [18]. [18] further defined morphology as the arrangement of members of an object and how these members combine to form a whole. In linguistic sense, an object signifies a word, while its parts or members refer to its constituent morphemes. Therefore, it is logical to define morphology as a branch of linguistics concerned with the morphotactics of a language, its realization from morphemes and applications. The study of morphology can either take a traditional (by human linguists) approach or computational approach. 
2010 Second International Conference on Computer Research and Development

Published: 2010

Natural Language Processing based on Semantic inferentialism for extracting crime information from text

2010 IEEE International Conference on Intelligence and Security Informatics

Published: 2010

Top Organizations with Patents on Technologies Mentioned in This Article

View More

A not-for-profit organization, IEEE is the world's largest technical professional organization dedicated to advancing technology for the benefit of humanity.

(C) Copyright 2020 IEEE - All rights reserved. Use of this web site signifies your agreement to the terms and conditions. 